\title{
Lifelong Learning and ICTs
}

\author{
http://dx.doi.org/10.3991/ijes.v3i2.4353 \\ Athanasios S. Drigas and Vasiliki Tsolaki \\ NCSR DEMOKRITOS, Institute of Informatics and Telecommunications, Net Media Lab, Athens, Greece
}

\begin{abstract}
- the purpose of this paper is to present a review of sample papers that have been published from 2003-2013 regarding lifelong learning and ICT. The use of ICT in lifelong learning is viewed in relation to different settings of learning i.e. formal, informal and non-formal learning, with special reference to the third-age. A special focus is also given on the technologies and specific tools which are used for the provision of lifelong learning. The role of ICT networks, web technologies in e-learning, mobile learning tools and virtual worlds as facilitators of knowledge sharing in all types of learning settings is examined.
\end{abstract}

Index Terms - collaborative e-learning, ICT, lifelong learning.

\section{INTRODUCTION}

Coffield stated in 1997 that lifelong learning not only embraces the compulsory phases of education but also includes activities in further and higher education as well as continuing education and training throughout life [33]. Lifelong learning and ICT are related with all settings of learning. This relation is investigated separately for each type of learning setting. In the formal education system several opinion surveys and studies have been conducted by universities. E-learning communities have been created in order to promote a connection between theory and practice. Electronic portfolios could be used to develop students' competence regarding lifelong learning skills and teacher's role becomes essential in the context of lifelong competence development. The increasing need for qualified staff with new skills for the new jobs that are created means that a special attention should be given to vocational training. Questionnaires and research conducted in small and medium enterprises confirm that e-learning is valuable for continuing education helping professionals to achieve the goal of lifelong learning. EU's funded projects also show the key role of public libraries in family learning provision. Interviews conducted with universities show that high value is given by academics in conference attendance and the use of the Internet.

Third-age is also examined in relation to lifelong learning, as the latter should be promoted to senior citizens too. Senior citizens' ICT skills can be developed through social networking and ICT can be used in order to help elderly people face the computer and its challenges in a more positive way.

In the fourth part of our review, we make an effort to present the technological developments that facilitate lifelong learning. During our research period, several projects have been conducted that reflect on ICT applications and their impact on lifelong learners' life. E-learning has brought a major contribution to educational issues as it can solve problems such as lack of materials and resources. Within this context, collaborative learning sup- ports lifelong learning in communities of e-learning practice. Research conducted in the field of collaborative mentor support showed that collaboration in communities of elearning practice within web-based professional networks facilitates active participation in lifelong learning activities.

Under this frame, it is investigated how membership in virtual learning communities can influence learner's life in professional terms. Social virtual worlds could be used as platforms for supporting lifelong learners with career and educational choices. The use of Web 2.0 and 3.0 virtual tools has indicated the interactive form of learning in the networked society. Learning networks are established to connect distributed learners and support seamless access to lifelong learning facilities.

Finally, in the most recent literature, the focus has been shifted to mobile learning which provides ubiquitous computing access. Passing from e-Learning to m-learning, mobile phones could promote lifelong learning and help lifelong learners create knowledge across their life.

\section{VARIOUS SETTINGS Of LIFELONG LEARNING}

\section{A. Formal and non-formal Learning}

\section{1) The role of universities and teachers}

Reference [1] exploring the role of communication and information technologies (C\&IT) in universities argued that their use is not as widespread as expected. Continuing professional development is as important as the flexible provision of a range of learning opportunities designed to promote lifelong learning. Open and distance learning opportunities based on C\&IT appear to be significant in achieving this flexibility. The most effective ways in which organizations can be networked to make the most of new technologies need to be determined and universities will need to adapt their continuing education function accordingly.

Lifelong learning skills such as the ability to solve problems, work both independently and in a team, communicate effectively in all formats and on all levels, and self-direct one's learning and professional development needs are required in the learning society. Reference [2] of Massey University in New Zealand explained that universities should take responsibility in preparing students for lifelong learning. The creation of electronic portfolios, with the aid of professional representatives, could help students develop their competence regarding lifelong learning skills.

The University of Las Palmas de Gran Canaria has conducted an opinion survey among its teachers about the use of Information Communication Technology (ICT) tools that are available in its virtual campus. According to the results of this survey which were presented by [3], the participants were willing to incorporate ICT into their 
daily practices, encouraging this way the university in its work on the integration of ICT tools wherever possible. By integrating ICT tools in every area where it is possible, the University meets the challenges of the new common European Space. Access to learning is increased, equal educational opportunities are provided for all and lifelong learning is ensured.

Another study was conducted during 2011 at an Australian university. In this study, presented by [4], the group of participants consists of undergraduate science communication students that worked in smaller teams to develop their knowledge in their subject matter by creating digital knowledge maps. According to the findings, the digital open-ended mapping improved students' lifelong learning skills. Students worked collaboratively with others and used effectively information and communication technologies, but they also gained greater control and ownership of their learning.

At the Faculty of Sport in the University of Ljubljana, the "Sportfolio.si" has been developed to ensure cooperation of sport students, professors and the mentors at school. Reference [5] developed the first e-learning community in Slovenia in the field of practical pedagogical training which allows students, assistant teachers and teachers "in practice" to exchange their experience and ideas, developing a partnership between theory and practice. According to the findings, this approach strengthens the community of teachers-mentors and students in practical pedagogical training and provides support for lifelong learning, promoting the development of competencies for a society of knowledge with the use of ICT.

Lifelong competence development is required in the knowledge-based economy. ICT can enhance the process of teacher training and this can be used for Lifelong Competence Development of teachers. In the frames of the EU-funded TENCompetence project, [6] explained how the use of a software platform for lifelong competence development can improve the in-service training of teachers. Teachers obtain the ability to teach ICT-enhanced competences which can be considered to be essential for every citizen and worker.

As regards the pedagogical integration of ICT, [7] described the importance of ICT in bringing changes to classroom teaching. The Second International Information Technology in Education Study 2006 (SITES 2006) was designed taking into account the pedagogical orientation of the teacher. It has already been found by previous studies (SITES M1 and M2) that classrooms that had recognized the potentials of ICT to promote the development of students' 21 st century skills tended to be more connected to people outside of the school. 21st century oriented pedagogical orientation, as opposed to traditionally important, could be further divided into lifelong learning and connectedness oriented.

\section{2) The role of enterprises}

Ref. [12] emphasized the need for qualified staff that will profit from lifelong learning outside formal educational systems. Working in the European information society involves being a highly qualified employee equipped with new skills that are required for the new jobs. Following from this, training of the working population will be a necessity in order to fulfill the labour market needs. Education and training systems as well as companies should think about ways to embrace the opportunity
ICT-enabled communities can offer. Under this scope online communities have the potential to respond to the needs for learning new skills for new jobs.

Ref. [13] investigated the possibility of developing elearning as an alternative way to conduct continuing education for public health nurses. A structured questionnaire was used to collect data by mailing methods conducted in Taiwan with 233 randomly selected public health nurses. The authors confirmed that asynchronous e-learning programs are an appropriate learning method for public health nurse continuing education. E-learning is a valuable learning model that could be adopted for all health care professionals, helping them to achieve the goal of lifelong learning.

The rapid development of ICTs influenced the educational branches of lifelong training, continuing vocational training and distance training. The arrival of modern webbased technologies and broadband networks also brought the arrival of e-learning and Open and Distance Learning (ODL), considering that most of the teaching is carried out remotely in space and time. Under this scope, [14] introduced the idea of virtual class for the electrical engineering sector which emphasized the need for the development of training courses connected with enterprise needs. And since individuals in order to maintain their employability need to return to education and training at different stages of their working life, it could be argued that lifelong learning has become a reality.

Innovations in ICTs and the development of electronic learning could prove very appealing to small and medium enterprises that have to deal with financial, attitudinal and technological barriers. Ref. [15] conducted a research in North Wales, which is a rural and peripheral area, exploring employee and employers' attitudes towards e-learning. According to the findings, electronic learning encounters obstacles such as employers' attitudes and the lack of the fundamentals of computer systems. A positive approach towards e-learning is required by both employers and employees to encourage engagement in future learning as a means of developing the skills of employees and owner/managers and providing access to new opportunities for learning and development. The establishment of learndirect centres in local communities where existing and potential employees can access personal and work-related learning, under the umbrella of the University for Industry (which was renamed 'learndirect') was an UK government initiative aimed to provide a national infrastructure for lifelong learning.

Ref. [16] introduced a specialization of the IEEE Learning Object Metadata (LOM) standard. This standard is used to support the description and classification of learning resources for rural small and medium enterprises (SMEs) in five European regions in the context of the Rural-eGov initiative. The design of an appropriate metadata schema for a digital learning repository (DLR) aiming to support vocational training of SMEs in rural areas is examined. According to the findings, agricultural professionals' lifelong learning needs could be covered with the aid of ICT, supporting by extension rural development.

\section{B. Informal Learning}

It is interesting enough to notice that ICT facilitates and supports adult informal learning too. Informal learning includes all aspects of life such as leisure interests, work 
and day-to-day life and is considered to be as important as formal learning context. Ref. [8] investigated how ICTs are used by adults for informal learning. According to their survey this area of ICT-based learning could contribute to fulfilling the potential of ICT to free learning from institutional barriers and allow learners to promote autonomous learning. Motivated informal learners seem to be more attracted by ICTs than motivated formal learners, therefore our understanding about ICT and informal learning need to be developed.

Within the wider context of lifelong learning, the importance of family learning has been recognized by the UK government and non-government agencies. Ref. [9] emphasized the need for family learning to be connected with informal learning. Public libraries can play a key role in the provision and development of family learning services. Being the main providers of information and communication technologies (ICT) in the community, libraries can be seen as the ideal place for family ICT with increased recognition of their role in today's society. As family learning has been strongly associated with social inclusion, it could make a major contribution within the field of lifelong learning.

Ref. [10] suggested that public libraries are moving away from the passive provision of information to a more active approach. The PULLS (Public libraries in the learning society) project which was funded by the EU's Socrates programme promoted the idea of the public library as an open learning centre in an attempt to enhance adults' information literacy through informal learning. By delivering ICT access and support, libraries have found a way to achieve a renewed interest in them and play a key role in the 21 st century. There is indeed a significant role for libraries to play in supporting both ICT skills and wider information literacy learning.

Ref. [11] suggested that lifelong learning should embrace the whole range of formal, non-formal and informal learning from pre-school to post-retirement. The findings of thirty six interviews conducted with fully qualified and tenured academics selected from Information Systems Schools in sixteen universities showed that high regard is given to informal learning. Information systems academics place great emphasis on structured ways of informal learning to interact with other academics. University administrators should take into consideration that conference attendance and the use of the Internet are highly valued by their academics when they develop their policy making.

\section{LIFELONG LEARNING AND The ThIRD AGE}

The use of new technologies in the knowledge-based society requires the possession of capabilities that would possibly lead to the exclusion of particular social classes and mostly the elderly. Lifelong learning programs should be developed to offer opportunities to senior citizens. In order for them to remain active participants and not to be excluded from social, cultural and economic life, the development of ICT skills has become fundamental. Ref. [17] described the approach and the results of a targeted learning course based on social networking, through which ICT skills can be developed.

Ref. [18] presented the results of a focus group within the Memory Line Project in Italy. The Grundtvig Socrates "Memory Line Project" aims at training senior and young citizens to collect records and save them in digital form in order to ensure their conservation within the area of lifelong training. An inter-regional and intergenerational learning model based on memory and communication is promoted. The project on the whole helped elderly people reconsider their negative attitude toward the computer and work together with the Net Gens by creating a communication channel based on mutual respect.

\section{TECHNOLOGY AND LIFELONG LEARNING}

Ref. [24] presented eLearning as a panacea for the educational problems of the developing world. ICTs are providing new opportunities for the developing countries by solving several educational issues such as the lack of study materials and resources. As education is considered to be the biggest user of computer software, in the frame of eLearning, virtual learning environments (VLEs) can improve or support learning and teaching. The emergence of Web 2.0 can further enhance the use of web technologies in eLearning and has the potential to support lifelong learning.

\section{A. Web 2.0 and virtual world technologies}

Ref. [19] presented a framework for the design of a distributed network to support lifelong learning in ICT networks. ICT networks are very promising for lifelong learning as they can be used to connect distributed learners and providers in a discipline to establish Learning Networks (LNs). The design model developed by the authors is based on self-organization theory and uses technologies such as software agents and open learning technology standards most of which have been developed by IMS (imsglobal.org), IEEE (ltsc.ieee.org) and AICC (aicc.org). In order to fulfill the set requirements, the Groove (Groove.net) platform was selected as it was easily to be customized. Despite the disadvantages of the framework, the authors argue that ICT networks can support seamless and ubiquitous access to lifelong learning facilities at home, at work, in school and universities.

Communities of practice (COPs) within an institutional context that provides lifelong learning should be governed by values, organization and specific strategies designed to suit practitioners engaged in democratic collaborative styles of learning. Ref. [20] presented the Joint Information Systems Committee (JISC) e-learning Independent Study Award (eLISA) and JISC infoNet Collaborative Approaches to the Management of e-learning (CAMEL) projects. Based on the working practices of these two elearning projects, two new theoretical collaborative team leadership and operational models are proposed to promote lifelong learning. It is argued that a distributedcoordinated collaborative team leadership model is more effective and that e-learning teams thrive in an atmosphere of trust and respect in the intentional communities of elearning practice.

Ref. [21] presented the MERIT simulation game within a blended learning program aiming at addressing the continuing professional development (CPD) needs in the Irish construction industry. Through the simulation game, collaborative learning would be facilitated with the aim to help participants improve their analytical skills and problem solving techniques in a construction organization. If the management of the integration of the simulation games is conducted in a careful and planned way, it can provide a very effective enhancement to the learning ex- 
perience for professionals who wish to undertake opportunities for continuing professional development.

Ref. [23] explored the ways in which membership in virtual learning communities (VLCs) can support lifelong learning. Through VLC membership, individuals may transform or develop their learning career and also make significant life changes. For communities to be successful in supporting individual change, they must provide a secure and supportive virtual environment. The community comfort zone gives members the opportunity to gain confidence in the real world, beyond the secure boundaries of the community.

Ref. [25] presented the EU funded collaborative project entitled 'NOVICE' under the Lifelong Learning Programme conducted with the collaboration of five European veterinary schools. This collaboration aimed to develop a web-based professional network for the veterinary profession, as far as the use of Web 2.0 tools (such as forums, instant messaging, voice calls and video conferencing, social networks etc.) is concerned. The results of the study indicated that the use of Web 2.0 tools for lifelong learning is likely to increase by the veterinary profession. Offering a number of advantages compared with face-to-face communities, participation in online communities promotes unintentional informal learning that would not otherwise be accessible.

With lifelong learning covering all learning activity throughout life, ICTs have been considered as enablers that can facilitate learning anytime and anywhere. Ref. [26] promoted the use of social networks for professional learning. Using Facebook for professional reasons is a new emerging phenomenon, since most empirical research on the use of social network sites has been conducted on the educational field. Considering Facebook groups as networks of practice (NoPs), the authors focus on the founders and the members of five Italian Facebook groups regarding the nature of discussion topics and groups membership, duration of membership and participation and the interplay between online and offline activities. Their findings suggest that the different thematic characterization of the groups has an impact on their membership in terms of the type of social capital and that group typology is correlated with the impact on real life of members in professional terms.

Ref. [27] indicated the importance of Web 2.0 and 3.0 virtual tools for lifelong learning. Learning is no longer acquired individually, but it rather occurs through interaction in a digital and connected society. In the networked society there is an increasing demand for e-skills. Three major types of e-skills are identified: ICT practitioner skills, ICT user skills and ICT business skills. E-skills and e-literacy have to coexist with soft skills that can be cultivated in social, collaborative and virtual contexts. With the collaborative web and the immersive $3 \mathrm{D}$ virtual worlds, students acquire new learning profiles and get more prepared for lifelong learning. Those who are not so familiar with computer need to adapt to this profile.

Ref. [28] focus upon how virtual worlds can be used in the context of education and training. Aiming to evaluate the efficacy of using Second Life (SL), a social virtual world, as a platform for supporting lifelong learners, the authors tested the efficacy of the four dimensional framework (learner, pedagogic models, representation and context). The possibilities of using a virtual world for support- ing lifelong learners in their career decisions and educational choices are explored in this study that was designed with two defined groups. The technical issues experienced by users on the day of the testing have led to the development of OpenSim by open source developers which allowed the application to be hosted behind the institutional firewalls. Although findings did not prove that SL could help learners with career decisions and educational choices, they indicated the power of the tool for supporting distributed learning communities based upon shared interests.

\section{B. From e-learning to m-learning}

Ref. [22] proposed an e-book interface that enables learners raise questions in a learning context. Their question is then issued in a discussion forum and a mentor is selected who should answer the question after having inspected the profile of the questioner and rated the difficulty of the question by a rating system. Learners can also use mobile phones to access the mobile discussion forum using voice/text without any constraints of time and place. According to the results of this study, most learners despite the usability problems benefited to a great degree from collaborative mentor support, which facilitated selfdirected learning and knowledge sharing for lifelong learning.

Education no longer being the exclusive privilege of the elite has become accessible to anyone. Distance learning and virtual classes have been added to classroom learning. Ref. [29] suggested that the use of technology can provide a flexible learning framework which is preferred by adult learners. The latter are equipped with devices that enable them to learn anywhere and everywhere providing educationalists with new opportunities. It is realized that formal content could also be learnt in informal surroundings, since most of the learning takes place out of the classroom. According to the authors' study defining a theory for mobile learning is crucial for the successful design of a mobile framework for lifelong learning.

Ref. [30] re-defined mobile learning in the conceptual framework of ubiquitous knowledge construction. From elearning to m-learning, the authors proposed an alternative definition of mobile learning that gives emphasis on "widespread", "just-in-time" and "when-needed" computing power for learners. In the m-learning infrastructure, mobile learners use ubiquitous computing technologies which are included in the aspects of mobile hardware, mobile software and mobile interface. Investigating pedagogies for mobile learning, their study interrelates mobile learning, constructivism and lifelong learning. Taking constructivism as the theoretical basis for attempts to solve the challenges of LLL, the width of ubiquity is expanded across the person's lifespan.

The Commonwealth for Learning (COL) has developed a framework for Lifelong Learning (L3) for Farmers assuming that open and distance learning (ODL) and ICT can facilitate self-directed learning among the marginalized sections of the rural communities. Ref. [31] studied the role of mobile phones as a learning tool for rural women in Southern India. This project undertaken with a non-governmental organization called "Vidiyal" was based on the premise that if the women developed business proposals to obtain credit to start up small enterprises, not only they would be able to repay the credit but also the banking sector would be encouraged to support L3 as 
a business strategy. In this study mobile phones were introduced as both learning tools and as tools for business. The control over technology, with elements of appropriation, objectification, incorporation and conversion, in the context of social capital, demonstrated that the transition from dependency on external authority for knowledge to creating knowledge is possible in non-formal learning settings. As for the gender, by the use of technology, lifelong learning can be promoted to women both in developing and developed countries.

\section{CONCLUSION}

In our review analysis, we tried to present ICT developments in the field of lifelong learning, covering all settings of learning. In the formal and non-formal context, universities should take account for their crucial role in connecting theory and practice. Students should develop, with teachers-mentors' help, their competence regarding lifelong learning skills. Vocational training should be associated with enterprise needs, with the aid of ICT, in order to help individuals maintain their employability. It is also shown that informal learning is highly estimated by academics providing opportunities for interaction with other academics. Family learning and public libraries with the help of ICT can help free learning from institutional barriers and attract informal learners. Lastly, senior citizens should be included in lifelong learning programs in order to take advantage of computer developments and support their social inclusion.

At the same time, we tried to collect all the technology associated with lifelong learning during the decade of our research. Collaboration has emerged as an essential element of knowledge sharing and self-directed learning in communities of e-learning practice [32]. E-learning can help overcome educational barriers and provides new opportunities for developing countries. Web 2.0 and 3.0 virtual tools facilitate social and professional interaction among lifelong learners. These tools can be accessible to learners whenever and wherever they need them and thus mobile learning meets the challenges of ubiquitous knowledge construction in today's lifelong learning framework. ICT has become enabler of learning anytime and anywhere. It remains to be seen to what extent this technology-based lifelong learning will be successfully promoted by policy makers to all individuals in society [33].

\section{REFERENCES}

[1] Osborne, M., \& Oberski, I. (2004). University continuing education: The role of communications and information technology. Journal of European Industrial Training, 28(5), 414-428. http://dx.doi.org/10.1108/03090590410533099

[2] Heinrich, E., Bhattacharya, M., \& Rayudu, R. (2007). Preparation for lifelong learning using ePortfolios. European Journal of Engineering Education, 32(6), 653-663. http://dx.doi.org/10.1080/ 03043790701520602

[3] Castro Sánchez, J. J., \& Chirino Alemán, E. (2011). Teachers' opinion survey on the use of ICT tools to support attendancebased teaching. Computers \& Education, 56(3), 911-915. http://dx.doi.org/10.1016/j.compedu.2010.11.005

[4] Hanewald, R. (2012). Cultivating Life-Long Learning Skills in Undergraduate Students through the Collaborative Creation of Digital Knowledge Maps. Procedia-Social and Behavioral Sciences, 69, 847-853. http://dx.doi.org/10.1016/j.sbspro.2012.12.007

[5] Majerič, M., Žvan, M., \& Kolenc, M. (2009). An example of an Elearning community for lifelong learning by physical education teachers. Acta Universitatis Palackianae Olomucensis. Gymnica, 38(1), 59-67.

[6] Stefanov, K., Naskinova, I., \& Nikolov, R. (2007). ICT-enhanced teacher training for lifelong competence development. Abstracts and Proceedings of the Joint IFIP Conference: WG3.1 Secondary Education, WG3.5 Primary Education: Informatics, Mathematics, and ICT: a 'golden triangle' IMICT 2007, CCIS, Northeastern University, Boston, MA, pp.55-56.

[7] Law, N. (2009). Mathematics and science teachers' pedagogical orientations and their use of ICT in teaching. Education and Information Technologies,14(4), 309-323. http://dx.doi.org/10.1007/ s10639-009-9094-z

[8] Selwyn, N., \& Gorard, S. (2004). Exploring the role of ICT in facilitating adult informal learning. Education, Communication \& Information, 4(2-3), 293-310. http://dx.doi.org/10.1080/14636310 412331304726

[9] Kirk, W., McMenemy, D., \& Poulter, A. (2004). Family learning services in UK public libraries: an investigation of current provision and ongoing development. New library world, 105(5/6), 176183. http://dx.doi.org/10.1108/03074800410536603

[10] Eve, J., de Groot, M., \& Schmidt, A. M. (2007). Supporting lifelong learning in public libraries across Europe. Library Review, 56(5), 393-406. http://dx.doi.org/10.1108/0024253071 $\underline{0750581}$

[11] Davey, B., \& Tatnall, A. (2007). The Lifelong Learning Iceberg of Information Systems Academics-A Study of On-Going Formal and Informal Learning by Academics. Journal of Information Technology Education, 6, 241-248.

[12] Ala-Mutka, L., \&Punie, Y. (2009). Learning and innovation in new ICT-facilitated communities. European Commission, retrieved June, 28, 2010.

[13] Yu, S., Chen, I. J., Yang, K. F., Wang, T. F., \& Yen, L. L. (2007). A feasibility study on the adoption of e-learning for public health nurse continuing education in Taiwan. Nurse Education Today, 27(7), 755-761. http://dx.doi.org/10.1016/j.nedt.2006.10. $\underline{016}$

[14] Drigas, A. S., Koukianakis, L. G., \&Glentzes, J. G. (2006). An ODL system and Virtual Class for the electrical engineering sector. E-learning, 1(2), 3.

[15] Sambrook, S. (2003). E-learning in small organisations. Education+ Training, 45(8/9), 506-516. http://dx.doi.org/10.1108/004 00910310508892

[16] Tzikopoulos, A., Manouselis, N., Yialouris, C. P., \&Sideridis, A. B. (2007, July). Using educational metadata in a learning repository that supports lifelong learning needs of rural SMEs. In EFITA/WCCA 2007 Conference on Environmental and rural sustainability through ICT, Glaskow, UK (July 2007).

[17] Repetto, M., \&Trentin, G. (2009). ICT and lifelong learning for senior citizens.Journal of e-Learning and Knowledge SocietyEnglish Version, 4(1).

[18] Pieri, M., \&Diamantini, D. (2011). Teachers of Life and ICT. World Journal on Educational Technology, 2(3), 158-168.

[19] Koper, R., Giesbers, B., Van Rosmalen, P., Sloep, P., Van Bruggen, J., Tattersall, C., \& Brouns, F. (2005). A design model for lifelong learning networks. Interactive Learning Environments, 13(1-2), 71-92. http://dx.doi.org/10.1080/10494820500173656

[20] Jameson, J., Ferrell, G., Kelly, J., Walker, S., \& Ryan, M. (2006). Building trust and shared knowledge in communities of e-learning practice: collaborative leadership in the JISC eLISA and CAMEL lifelong learning projects. British Journal of Educational Technology, 37(6), 949-967. http://dx.doi.org/10.1111/j.1467-8535.2006. 00669.x

[21] Wall, J., \& Ahmed, V. (2008). Use of a simulation game in delivering blended lifelong learning in the construction industryOpportunities and Challenges. Computers\& Education, 50(4), 1383-1393. http://dx.doi.org/10.1016/j.compedu.2006.12.012

[22] Wei, F. H., \& Chen, G. D. (2006). Collaborative mentor support in a learning context using a ubiquitous discussion forum to facilitate knowledge sharing for lifelong learning. British journal of educational technology, 37(6), 917-935. http://dx.doi.org/10.1111/ j.1467-8535.2006.00674.x

[23] Allan, B., \& Lewis, D. (2006). The impact of membership of a virtual learning community on individual learning careers and pro- 
fessional identity. British Journal of Educational Technology, 37(6), 841-852. $\quad$ http://dx.doi.org/10.1111/j.1467-8535.2006. $\underline{00661 . x}$

[24] Nawaz, A. (2013). Using e-learning as a tool for 'education for all'in developing states. International Journal of Science and Technology, 4(3), 38-46.

[25] Dale, V. H. M., Kinnison, T., Short, N., May, S. A., \& Baillie, S. (2011). Web 2.0 and the veterinary profession: current trends and future implications for lifelong learning. Veterinary Record, 169(18), 467-467. http://dx.doi.org/10.1136/vr.d4897

[26] Ranieri, M., Manca, S., \& Fini, A. (2012). Why (and how) do teachers engage in social networks? An exploratory study of professional use of Facebook and its implications for lifelong learning. British Journal of Educational Technology, 43(5), 754-769. http://dx.doi.org/10.1111/j.1467-8535.2012.01356.x

[27] Loureiro, A., Messias, I., \&Barbas, M. (2012). Embracing Web $2.0 \& 3.0$ tools to support lifelong learning-Let learners connect. Procedia Social and Behavioral Sciences, 46, 532-537. http://dx.doi.org/10.1016/j.sbspro.2012.05.155

[28] De Freitas, S., Rebolledo-Mendez, G., Liarokapis, F., Magoulas, G., \&Poulovassilis, A. (2010). Learning as immersive experiences: Using the four-dimensional framework for designing and evaluating immersive learning experiences in a virtual world. British Journal of Educational Technology, 41(1), 69-85. http://dx.doi.org/10.1111/j.1467-8535.2009.01024.x

[29] Nordin, N., Embi, M. A., \&Yunus, M. M. (2010). Mobile learning framework for lifelong learning. Procedia-Social and Behavioral Sciences, 7, 130-138. http://dx.doi.org/10.1016/j.sbspro.2010. $\underline{10.019}$

[30] Peng, H., Su, Y. J., Chou, C., \& Tsai, C. C. (2009). Ubiquitous knowledge construction: Mobile learning re-defined and a conceptual framework. Innovations in Education and Teaching International, 46(2), 171-183. http://dx.doi.org/10.1080/147032909028 $\underline{43828}$

[31] Balasubramanian, K., Thamizoli, P., Umar, A., \&Kanwar, A. (2010). Using mobile phones to promote lifelong learning among rural women in Southern India. Distance Education, 31(2), 193 209. http://dx.doi.org/10.1080/01587919.2010.502555

[32] De Freitas, S., \& Jameson, J. (2006). Collaborative e-support for lifelong learning. British Journal of Educational Technology, 37(6), 817-824. http://dx.doi.org/10.1111/j.1467-8535.2006.006 $\underline{65 . x}$

[33] Selwyn, N., \& Gorard, S. (2003). Exploring the 'new' imperatives of technology-based lifelong learning. Research in PostCompulsory Education, 8(1), 073-092. http://dx.doi.org/10.1080/ $\underline{13596740300200141}$

\section{AUTHORS}

Athanasios Drigas is a Senior Researcher at N.C.S.R. Demokritos. He is the Coordinator of Telecoms Lab and founder of Net Media Lab since 1996. From 1985 to 1999 he was the Operational manager of the Greek Academic network. He has been the Coordinator of Several International Projects, in the fields of ICTs, and e-services (elearning, e-psychology, e-government, e-inclusion, eculture etc). He has published more than 240 articles, 7 books, 25 educational CD-ROMs and several patents. He has been a member of several International committees for the design and coordination of Network and ICT activities and of international conferences and journals. Finally he has received many distinctions for projects, articles and patents. (dr@iit.demokritos.gr).

Vasiliki Tsolaki is Education, Development and Quality Assurance Manager at the Institute of youth and lifelong learning. She is also a researcher and has participated in research projects regarding Lifelong Learning at N.C.S.R. Demokritos. (vasilikitsolaki@hotmail.com).

Submitted 24 December 2014. Published as resubmitted by the authors 12 May 2015. 